\title{
PSYCHOPATHIC DEVIATE TENDENCY AND PSYCHOPATHOLOGY RELATIONSHIPS IN AN IRANIAN ADOLESCENTS AND YOUTH SAMPLE: GENDER DIFFERENCES AND PREDICTORS ${ }^{* *}$
}

(Received: 20 July 2009; accepted: 7 January 2010)

\begin{abstract}
The present study examines psychopathic deviate tendency and psychopathology relationships and the possible gender differences in them in an Iranian adolescents and youth sample. The sample included 106 adolescents ( 55 females and 51 males) and 94 youth (45 females and 49 males) that were randomly selected from Eghlid city, Fars province, Iran. We speculated a possible linkage between psychopathology and psychopathic deviate tendency among adolescents and youth on the basis of developmental psychopathology and related literature. A demographic questionnaire, the Minnesota Multiphasic Personality Inventory-2, scale-4, and the Symptom Check List 90 Revised were used in this study. Analysis indicated that psychopathic deviate tendency and psychopathology indices were linearly related in adolescents and youth. There are significant positive correlation coefficients between the psychopathic deviate tendency and psychopathology including somatisation, obsessive-compulsive disorder, anxiety, interpersonal sensitivity, aggression, phobia, paranoid ideation, psychosis, atypical factors and SCL-90-R. However, significant correlations between psychopathic deviate tendency, somatisation and phobia are elements that give a new insight into this research. A multivariate analysis of variance conducted by gender-age group and gender-age group interaction as independents and the psychopathic deviate tendency and psychopathology indices as dependents variables that reject their significant effects in both dependents' variables. Finally, the multiple regressions indicated that paranoid ideations, somatisation and aggression, somatisation, depression, and somatisation predict psychopathic deviate tendency in females, males, adolescence, youth, and total sample respectively.
\end{abstract}

Keywords: psychopathic, somatisation, obsessive-compulsive, anxiety, interpersonal sensitivity, aggression, phobia, paranoid, psychosis, adolescents, youth

\footnotetext{
${ }^{*}$ Siamak Khodarahimi, Islamic Azad University - Eghlid Branch, Eghlid, Fars, Iran; khodarahimi@yahoo.com.

** This work was supported by the Islamic Azad University - Eghlid Branch, Eghlid, Fars, Iran.
} 
Zusammenhänge zwischen psychopathischer Neigung zu Devianz und Psychopathologie bei einer Stichprobe von iranischen Jugendlichen und jungen Erwachsenen: Geschlechtsspezifische Unterschiede und Prädiktoren: Die vorliegende Studie untersucht die Zusammenhänge zwischen psychopathischer Devianz und Psychopathologie und mögliche geschlechtsspezifische Unterschiede bei einer Stichprobe von iranischen Jugendlichen und jungen Erwachsenen. Die Stichprobe bestand aus 106 in der iranischen Stadt Eghlid in der Provinz Fars zufällig ausgewählten Jugendlichen (55 Mädchen und 51 Jungen) sowie 94 jungen Erwachsenen (45 Frauen und 49 Männer). Aufgrund der Erkenntnisse der Entwicklungspsychopathologie und der einschlägigen Literatur nahmen wir an, dass bei Jugendlichen und jungen Erwachsenen ein Zusammenhang zwischen Psychopathologie und der Neigung zu psychopathischer Devianz bestehen könnte. Bei der Untersuchung wurden ein demographischer Fragebogen, die 4. Skala des Persönlichkeitstests Minnesota Multiphasic Personality Inventory - 2 (MMPI-2) sowie die Skala des Symptom Check List 90 Revised (SCL-90-R) verwendet. Die Analyse ergab, dass bei Jugendlichen und jungen Erwachsenen ein linearer Zusammenhang zwischen Neigung zu psychopathischer Devianz und psychopathologischen Faktoren besteht. Signifikant positive Korrelationskoeffizienten sind zu finden für psychopathische Neigung zu Devianz und psychopathologische Faktoren wie Somatisierung, Zwang, Angst, interpersonale Sensibilität, Aggression, Phobie, Paranoia, Psychose, atypische Faktoren bzw. die gesamte SCL-90-R-Skala. Als neues Ergebnis in diesem Forschungsbereich besonders hervorzuheben ist die Korrelation zwischen Neigung zu psychopathischer Devianz und Somatisierung bzw. Phobie. Bei der multivarianten Varianzanalyse, bei der als unabhängige Variablen das Geschlecht, die Altersgruppe sowie die Interaktion zwischen Geschlecht und Altersgruppe, als abhängige Variablen die Neigung zu psychopathischer Devianz und die psychopathologischen Parameter verwendet wurden, ergab sich eindeutig, dass diese Faktoren keine wesentliche Rolle bezüglich einer der abhängigen Variablen spielten. Des Weiteren zeigte die multiple Regressionsanalyse, dass die Neigung zu psychopathischer Devianz bei den Mädchen anhand paranoider Denkinhalte, bei den Jungen anhand von Somatisierung und Aggression, bei den Jugendlichen anhand von Somatisierung, bei den jungen Erwachsenen anhand von Depression und in der Gesamtstichprobe anhand von Somatisierung vorherzusagen ist.

Schlüsselbegriffe: Psychopathie, Somatisierung, Zwang, Angst, interpersonale Sensibilität, Aggression, Phobie, Psychose, Jugendliche, junge Erwachsene

\section{Introduction}

Psychopathic deviate, sociopathy, aggression, violence and antisocial behavior in adolescents and the young may impede their global success in the future, and it is harmful both for them and society. Historically, the origins of contemporary conceptualisations of psychopathy could be traced to H.M. CLECKLEY's (1976) influential monograph The Mask of Sanity. He regarded psychopathy as an alloy of personality features such as deficient affective response, superficial charm, and severe behavioral maladjustment in irresponsibility and promiscuity forms. His classic conceptualisation of psychopathy composed of both behavioral and personality characteristics. Psychopathic tendency is mostly directed to causing harm to others, but some scholars also include suicide and self-mutilation as forms of harm to self. Acts that intentionally cause physical hate or injury to others would fit within most definitions. A psycho- 
pathic construct involves a set of traits and behaviors that predispose the individual to engage in dishonest, hurtful, unfaithful behavior, and at times it is dangerous to one's own mental health. Thus, the opposite of psychopathy might be called the scrupulosity character. The psychopathy defined as a psychological gratification in destructive, criminal, sexual, or aggressive impulses and the inability to learn from past mistakes, seems to accompany any mental disorder symptom. In its full form, psychopathy is referred to as antisocial personality disorder in mental disorders (American Psychiatric Association 2004). It is characterised by a general tendency to disregard laws and rules, frequent reciprocal difficulties in intimate relationships, disturbed internalisation of moral standards and codes, and a diminished sensitivity to the needs and rights of the others. Psychopathics often show aggressive and violent behavior, and are overrepresented among criminals and prisoners. It also linked with problematic, unethical, and abusive conduct in workplace and social systems. Psychopathy, as an engendered construct, is much more common among men than women (WIDIGER \& COSTA 1994). Psychopathy has an early childhood onset and long enduring course through adulthood (FORTH \& BURKE 1998). HARRIS et al. (1994) argued that its early onset as an idiosyncratic feature could differentiate this syndrome from the others' personality and mental disorders. Specifically, children with previous attention deficit, hyperactivity, impulsivity, and the conduct problems resembled adult psychopaths more and have been categorised as fledgling psychopaths (KAZDIN 1987, 1993; GRESHAM et al. 2000). Altogether, these findings adhered to a psychopathy and psychopathology linkage implicitly.

Psychopathy has an overt or covert manifestation which is verbally and physically harmful to other people, animals, and properties, including behaviors that violate social expectations in any given environment; then it is destructive to the mental health of individual, family, and friends, and the community. Although the study of psychopathy and antisocial behavior is the most abundant (COSTELLO \& ANGOLD 2000), there is a lack of evidence for its relationship with individuals' mental health status. VAUGHAN \& OLDHAM (1997) divide psychopathy into two components: the presence of antisocial, and the absence of prosocial behavior. They noted that the presence of antisocial components includes anger, impulsivity, aggression, and disobedience. But a prosocial behavior deficit component involves lack of communication, affirmation, and cooperation skills. They concluded that psychopathy is associated with poor modulation of emotions, anger, difficulty delaying gratification, novelty seeking, and lack of prosocial behaviors. With regard to their conceptualisation, it would predict a negative relationship between psychopathy and individual mental well being.

Similarly, NIMH (1999) revealed that the development of psychopathy in adolescence is linked to mental health problems, particularly depression and externalising behaviors. LIPSEY \& DERZON (1998) in a meta-analysis of 34 prospective longitudinal studies of antisocial behavior found that having a psychological disorder was the strongest predictor of psychopathy in adolescence and young adulthood. It suggested that the older the age of onset, the fewer the number of psychopathic adolescents and youths will engage in seriously violent and antisocial behavior. Research indicated that psychopathic individuals have other mental disorders such as anxiety and depres- 
sion (KUTASH \& RIVERA 1996; KESSLER \& WALTERS 1998; NIMH 1999; BENNING et al. 2005). In addition, psychopathy is more closely linked to psychopathological variables in girls than in boys, and it related to the dissociative and depressive symptoms among girls and boys respectively (CHABROL et al. 2009). Thus, psychopathology may play a crucial role in psychopathy among adolescents and in both genders.

Moreover, research supported the three reflecting affective, interpersonal, and behavioral symptoms components in psychopathy (HALL et al. 2004). Psychopathic behavior was associated with negative emotionality, emotional disinhibition, reactive aggression, and poor adaptive functioning. Psychopathic violence was characterised as predatory or pillaging aggression, as opposed to affective or sentimental aggression (MELOY 1988). Severe psychopathic violent conduct in men has been empirically linked to a serious mental illness, i.e. psychosis and violence towards others (DEAN et al. 2007). A recent study showed very high levels of psychiatric morbidity, psychotic, mood and personality disorders at a very high rate in women who had been incarcerated for a major violent offence (LOGAN \& BLACKBURN 2009). On the other hand, mentally healthy individuals enjoy a positive quality of life; function well in different situations; and are free of symptoms of psychopathology (HOAGWOOD et al. 1996).

In sum, based on a life course model of antisocial behavior (EDDY \& REID 2001) it can be expected that mental illness can occur at any point in time during a child's life, and it may reactivate the childhood precursors of psychopathy in later stages. However, there is no single theory for psychopathy that explains psychopathy and psychopathology relationships in adolescence and youth periods. The developmental psychopathology theories implicitly suggest that psychopathy has various risk factors, and in return it endangers individual's mental health. For example, dysfunctional aspects of family life such as parental discord and parents' psychopathology can predispose people for antisocial personality disorders in later life (RUTTER 1979). Alternatively, some evidence designated two ways for psychopathy vulnerability in adolescents: (1) to encourage such persons to interact with better adapted youths under supervision of a mental health professional, and (2) improving parenting skills during childhood (FELDMAN et al. 1983; PATTERSON et al. 1993). Recent scholars suggest that better peer relations serve as buffering against psychopathy during adolescence (WEIKART 1998).

Therefore, we speculated a possible linkage between psychopathology and a psychopathic deviate tendency among adolescents and youth which originated in the developmental psychopathology and related literature. The main object of the present study is to investigate psychopathology and psychopathic deviate tendency relationships in Iranian adolescents and a youth sample. The first hypothesis of this research study is that psychopathology and psychopathic deviate tendencies have significant relationships among adolescents and youth. The second hypothesis of this research study is that there are significant differences among adolescents and youth in psychopathology and psychopathic deviate tendency in both males and females. The third hypothesis of this project is that psychopathological indices will predict psychopathic deviate tendencies in the Iranian sample. 
PSYCHOPATHIC DEVIATE TENDENCY AND PSYCHOPATHOLOGY RELATIONSHIPS 103

\section{Method}

\subsection{Participants}

The research population included adolescents (11-19 years old) and youth (20-29 years old) in Eghlid city, the north of the Fars province of Iran, where the Islamic Azad University - Eghlid Branch is located. The sample included 106 adolescents $(N=106, F=55, M=51)$ and 94 youth $(N=94, F=45, M=49)$. Participants were randomly selected from adolescents and the youth population from Eghlid city. After informed consent was acquired, a demographic questionnaire and two inventories were completed by the participants.

\subsection{Instruments}

The demographic questionnaire included age, gender, level of education, marital status, socioeconomic status, ethnicity and the occupation of parents. The two inventories used were (1) the Minnesota Multiphasic Personality Inventory-2, Scale-4 (MMPI-2, Scale-4), and (2) the Symptom Check List 90 Revised (SCL-90-R).

Minnesota Multiphasic Personality Inventory-2 (MMPI-2, Scale 4-PD): The MMPI developed by Hathaway and McKinley (1940), is one of the most frequently used clinical tests. Similarly, MMPI-2 was invented for both clinical and non-clinical applications (BUTCHER et al. 1989). MMPI-2 is a valid revision and expansion of the original MMPI, and they assert that continuity with the previous empirical literature has been assured. The original validity and clinical scales have been kept virtually intact in the MMPI-2. According to them, new norms provide a sounder comparative base. PARKER et al. (1988) found similar results, with reliability coefficients averaging 74. Comparable results were found for the MMPI-2 (BUTCHER et al. 1990). HASKELL (1996) ${ }^{1}$ showed that there are no significant differences between the multi ethnic groups on clinical item types of MMPI-2 for the Middle East including Iranian. MMPI-2 mostly employed the standardised psychological test for mental disorders in Iran for both screening and research purposes (MOUSAVINASAB et al. 2007; KHODARAHIMI 2010) ${ }^{2}$. The MMPI-2 has been validated in Iran and multiple groups have received training at numerous academic centers resulting in excellent inter-rater reliability (DUCKWORTH \& ANDERSON 1995). Also MMPI-2 validity using clinical endpoint analysis in areas of cultural diversity was affirmed in Iran (MOKHBER et al. 2008).

Here, we used MMPI-2, Scale 4 or Psychopathic Deviate. This scale measures conflict, struggle, anger and respect for society's rules. The PD scale was originally

\footnotetext{
${ }^{1} \mathrm{PhD}$ Dissertation in Psychology, Texas Tech University, USA.

${ }^{2}$ MoOTABI F. (1995) 'Preparation and Normalization of MMPI-2 Questionnaire in Tehran City Master Thesis in Clinical Psychology' (Unpublished personal communication, Iran University of Medical Sciences, Tehran).
} 
developed to identify patients diagnosed as a psychopathic personality, asocial or amoral type. General social maladjustment and the absence of strongly pleasant experiences are assessed by the 50 items included in Scale 4. Scores on Scale 4 tend to be related to age. All 50 items in the original scale have been retained in the MMPI-2 validation in the Iranian population. Often Iranian adolescents and college students scoring in the PD scale have a T-score range of 55 to 60 . This subscale operates somewhat as a measure of rebelliousness, the higher scorers show rebellion and its lower scorers indicate an acceptance of authority and the status quo. High scorers are very likely to be diagnosed as having some form of psychopathic personality disorder. But low scorers are mostly described as being conventional, conforming, and submissive.

Symptom Check List 90 Revised (SCL-90-R): The SCL-90-R invented for mental health screening purpose by DEROGATIS in 1977. SCL-90-R contained 90 items and including: Somatisation (12 items), obsessive-compulsive (9 items), anxiety (10 items), interpersonal sensitivity ( 9 items), depression (13 items), aggression (6 items), phobia ( 7 items), paranoid (6 items), psychosis (10 items), and atypical ( 7 items) scales (CYR et al. 1985). In addition, it has a total scale score index. SCL-90-R reliability was confirmed by Derogatis in 1976. SCL-90-R reliability fluctuated from $r=0.90$ for depression factor as the highest and $r=0.77$ as the lowest for psychosis factors. SCL-90-R validity with MMPI was the highest for depression $(r=0.73)$ and the lowest $(r=0.36)$ for phobia factors. Marashi $(1995)^{3}$ was reported SCL-90-R reliability by internal consistency alpha as follows: Somatisation $(\alpha=0.84)$, obsessivecompulsive $(\alpha=0.91)$, interpersonal sensitivity $(\alpha=0.82)$, depression $(\alpha=0.93)$, anxiety $(\alpha=0.86)$, aggression $(\alpha=0.90)$, phobia $(\alpha=0.83)$, paranoid $(\alpha=0.81)$, psychosis $(\alpha=0.84)$ and total scale $(\alpha=0.98)$. Additionally, SCL-90-R was standardised for the Iranian population and its validity and reliability affirmed too (FARJAD 1995; KHODARAHIMI et al. 2009).

\section{Findings}

Initial analysis of the data included a correlation coefficient that was conducted to evaluate relationships between the psychopathic deviate tendency and psychopathology indices, i.e. somatisation, obsessive-compulsive, anxiety, interpersonal sensitivity, aggression, phobia, paranoid, psychosis, atypical factors and SCL-90-R total score. This was computed among the 12 variables in an effort to assess to what degree these quantitative variables were positive and linearly related in the sample. Thus, analysis indicated that the psychopathic deviate tendency and the psychopathology indices were significantly and linearly related in adolescents and youth. The Bonferroni approach was used as a control for Type I effort across the 12 correlations, a $p$-value of less than 0.05 was used as an indicator for significance (Table 1).

\footnotetext{
${ }^{3}$ MARASHI, S.M. (1995) 'The Comparison of Social Adjustment and Mental Health among Employed and Unemployed War Handicapped Individuals in Ahvaz City - Master's Thesis in Psychology' (Unpublished personal communication, Iran University of Medical Sciences, Tehran).
} 
PSYCHOPATHIC DEVIATE TENDENCY AND PSYCHOPATHOLOGY RELATIONSHIPS 105

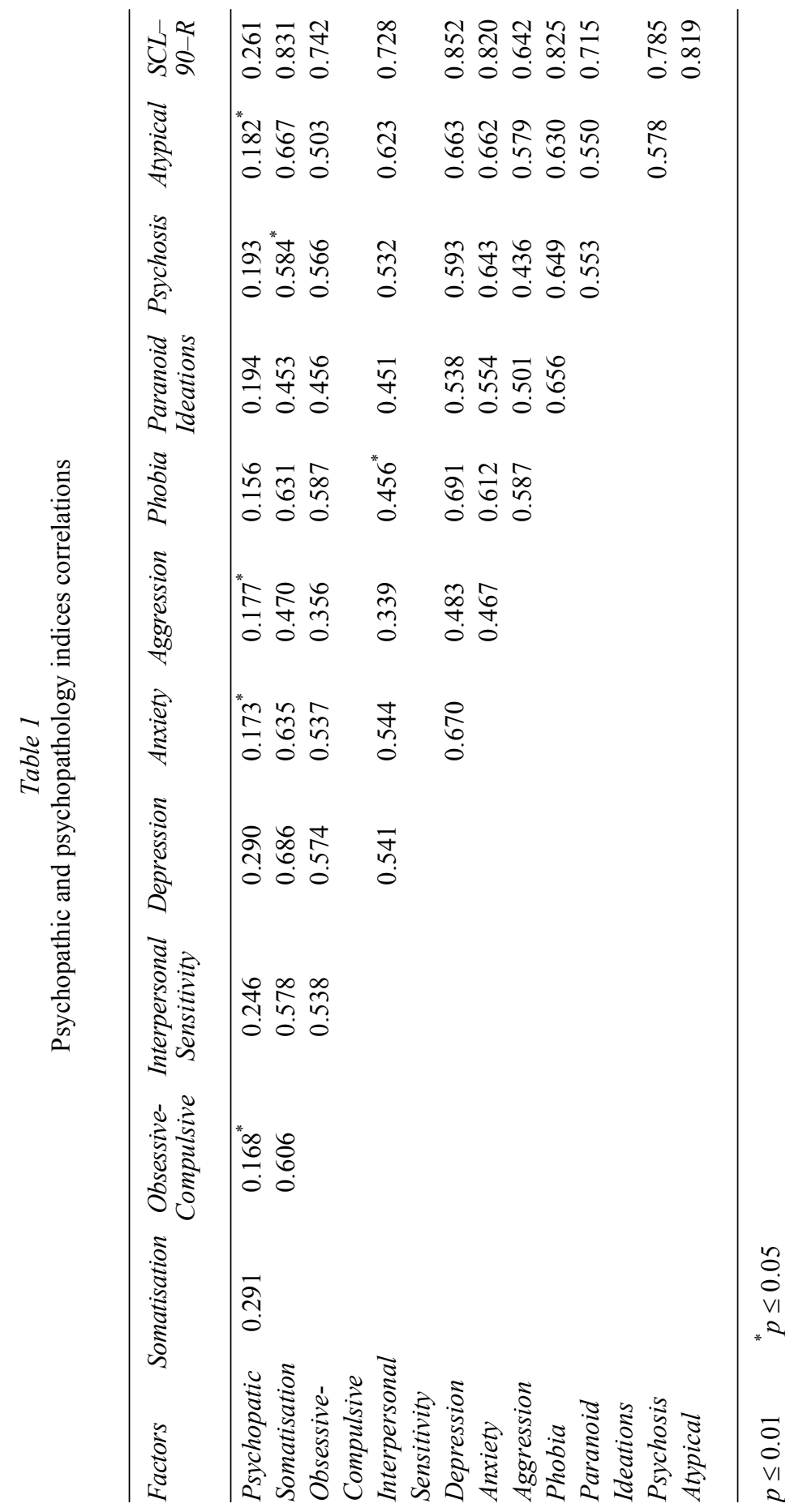


The second hypothesis of this research study is that age group, i.e. adolescence and youth periods, and gender plays a significant role in psychopathic deviate tendency and psychopathology. A $t$-test for independent groups was conducted to evaluate the effects of age group and gender for both the psychopathic deviate tendency and psychopathology indices separately, and the initial analysis did not show any significant effects for both of the age groups and gender. Additionally, to examine possible gender differences and age groups interaction, a multivariate analysis of variance (MANOVA) was conducted by gender, age group and gender-age group interaction as independents and the psychopathic deviate tendency and psychopathology indices as dependents variables. An overall multivariate effect was found for gender (Wilks' $k=0.952 ; F(11,186)=0.860 ; p<0.581)$, age group $($ Wilks' $k=0.940 ; F(11,186)=$ $1.070 ; p<0.388$ ), and gender-age group interaction (Wilks' $k=0.949 ; F(11,186)=$ 0.904; $p<0.538$ ), which rejects their significant effects in both psychopathic deviate tendency and psychopathology indices variables.

Finally, multiple regression analyses were conducted to evaluate the relationships of psychopathology indices (11 factors) and psychopathic deviate tendency by gender, age group and total sample. Findings indicated: (1) paranoid ideations $(13 \%)$, somatisation and aggression (16\%), (2) somatisation (4\%) and depression (18\%), and (3) somatisation $(8 \%)$ was predicted in psychopathic deviate tendency in females, males, adolescence, youth, and total sample respectively (Table 2).

Table 2

Multiple stepwise regressions for psychopathology indices and psychopathy prediction by gender, age group and total sample

\begin{tabular}{|c|c|c|c|c|c|c|}
\hline Groups & Entered variables & $R$ & $R 2$ & Beta & $T$ & $P$ \\
\hline Female & Paranoid Ideations & 0.365 & 0.133 & 0.370 & 3.884 & 0.0001 \\
\hline \multirow[t]{2}{*}{ Male } & Somatisation & 0.304 & 0.092 & 0.211 & 3.154 & 0.002 \\
\hline & $\begin{array}{l}\text { Somatisation \& } \\
\text { Aggression }\end{array}$ & 0.401 & 0.161 & 0.311 & 4.21 & 0.0001 \\
\hline Adolescence & Somatisation & 0.212 & 0.045 & 0.126 & 2.207 & 0.029 \\
\hline Youth & Depression & 0.429 & 0.184 & 0.259 & 4.551 & 0.0001 \\
\hline Total sample & Somatisation & 0.291 & 0.084 & 0.183 & 4.273 & 0.0001 \\
\hline
\end{tabular}

\section{Discussion}

The results from this study in the first hypothesis demonstrated that there are significant positive correlation coefficients between the psychopathic deviate tendency and all of the psychopathology indices involving somatisation, obsessive-compulsive, anxiety, interpersonal sensitivity, aggression, phobia, paranoid, psychosis, atypical fac- 
tors and SCL-90-R in this particular sample. The present study supported psychopathic deviate tendency and psychopathology linkage in Iranian adolescents and the youth sample.

Present findings are in line with HARE's (2003) conceptualisations that assumed psychopathy to include a range of mental symptoms, i.e. a grandiose sense of selfworth, impulse control problems, irresponsibility, inability to tolerate boredom, pathological narcissism, shallow affect, aggressive or violent tendencies, lack of empathy, a sense of extreme entitlement, poor judgment, failure to learn from experience, lack of personal insight, and failure to follow any life plan. Also, these findings are congruent with previous literature that confirmed relationships between psychopathy and anxiety, depression, impulsivity, aggression, paranoia, interpersonal conflicts, and psychosis disorders (ZAGON \& JACKSON 1994; HARE 1998; FRICK et al. 1999; NIMH 1999; LORBER 2004; WiLliams \& PAUlHUS 2004; DEAN et al. 2007; ChABrol et al. 2009; LOGAN \& BLACKBURN 2009). However, significant correlations between psychopathy deviate tendency, somatisation and phobia are something that highlights a new insight into this research. It can show the comorbidity of mental health and psychopathy in adolescents and youth, and would be related to psychopathy cultural contexts in Iran.

In addition, the results from this study in the second hypothesis indicated that gender, age group and their interaction does not have any significant effects on either the psychopathic deviate tendency or the psychopathological indices. However, this finding is in contrast to previous outcomes (EDDY \& REID 2001; GLENN et al. 2007).

Finally, the results from the multiple regressions in the third hypothesis found that paranoid ideations, somatisation, aggression and depression predicted psychopathic deviate tendency among females, males, adolescents, youth and total sample, respectively. Here, all independent variables had significant positive relationships to the psychopathic deviate tendency. It seems that these psychopathological predictive factors indicate both internal and external manifestations of psychopathy. It is thought that when individuals typically make external interpretations regarding their behavior, it would be expected that paranoid ideations and aggression are more related to psychopathy. But while the individuals typically use internal attributions respecting their performance, it would anticipate that somatisation and depression have a closer relationship to psychopathy. We can explain these predictive factors as internalisation and externalisation aspects of a psychopathic construct that can be traced to infantile and childhood experiences, i.e. identification, attachment, psychosocial and psychosexual development (BANDURA 1977; BOwLBY 1980, 1988; SHAVER \& CLARK 1994) ${ }^{4}$. This is the reason why these constructs are responsible for a wide variety of a child's repertoire of behavior. Another plausible explanation for the aforementioned finding is specific socio-cultural underpinnings of violent behavior across societies. Children are more likely to imitate the behavior of those that they consider to be in

${ }^{4}$ JefFrey, A.C. (1996) 'Predictors of Male Violence in Dating Relationships - Master's Thesis in Psychology' (Unpublished personal communication, Virginia Polytechnic Institute and State University Blacksburg). 
a position of power or who possess objects or characteristics that they would someday like to have. Psychopathy is but one of a full repertoire of coping skills that the child has identified over the years with some significant figures and may select them from the familial or other social contexts. However, if in any given situation, when the childas-adult has no other skills that help to prove successful encounters in resolving conflicts, then he or she will grasp the introjected model of psychopathy as a potential means to cope with present frustrations. In conclusion, current research adds to the psychology literature because of psychopathy and psychopathology relationships among adolescents and youth. However, the present research is limited because of a single measure used to assess psychopathy deviate tendency, and further research may apply other well established scales such as the Psychopathy Checklist-Revised (COOKE et al. 2001). It is expected that further research will be carried out to investigate the roles of socio-cultural structures in psychopathology and psychopathic tendency interrelatedness in Iranian society. Finally, it is anticipated that psychopathy dichotomies i.e., behavioral and personality, antisocial and prosocial, internalisation and externalisation, both covert and open, will be taken into consideration in future cross cultural and clinical studies.

\section{References}

American Psychiatric Association (2004) Diagnostic and Statistical Manual of Mental Disorders (Washington, DC: APA).

BAndurA, A. (1977) Social Learning Theory (Prentice Hall: Englewood Cliffs, NJ).

BenNing, S.D., C.J. PATRICK, D.M. Blonigen, B.M. Hicks \& W.G. IACONO (2005) 'Estimating Facets of Psychopathy from Normal Personality Traits: A Step toward Community Epidemiological Investigations', Assessment 1, 3-18.

Bowlby, J. (1980) Loss: Sadness and Depression vol. 3 of Attachment and Loss (New York: Basic Books).

BowlBy, J. (1988) A Secure Base (London: Routledge).

Butcher, J.N., W.G. DAhlstrom, J.R. Graham, A. TEllegen \& B. Kaemmer (1989) Minnesota Multiphasic Personality Inventory-2 (MMPI-2): Manual for Administration and Scoring (Minneapolis: Minnesota UP).

Butcher, J.N., J.R. GRAHAM, W.G. DAHLSTrom \& E. BOWMAN (1990) 'The MMPI-2 with College Students', Journal of Personality Assessment 54, 1-15.

Chabrol, H., C. Saint-Martin, N. Sejourné \& O. Moyano (2009) 'Contribution of Dissociative Symptoms to Antisocial Behavior in a Sample of High-School Students', L'Encéphale $35,52-56$.

Cleckley, H.M. (1976) The Mask of Sanity (5th ed.; St. Louis, MO: Mosby).

COOKE, D.J., D.S. Kosson \& C. MichIE (2001) 'Psychopathy and Ethnicity: Structural, Item and Test Generalizability of the Psychopathy Checklist-Revised (PCL-R) in Caucasian and African American Participants', Psychological Assessment 4, 531-42.

Costello, E.J. \& A. Angold (2000) 'Bad Behavior: An Antisocial Perspective on Disorders of Conduct' in J. HiLl \& B. MaUghan, eds. Conduct Disorders in Childhood and Adolescents (Cambridge: Cambridge UP) 1-31. 
CYR, J.J., J.M. MCKenNA-Foley \& E. PEACOCK (1985) 'Factor Structure of the SCL-90-R: Is there One?', Journal of Personality Assessment 49, 571-78.

Dean, K., E. Walsh, C. Morgan, A. Demjaha, P. Dazzan, K. Morgan, T. Lloyd, P. FEARON, P.B. JONES \& R.M. MURRAY (2007) 'Aggressive Behaviour at First Contact with Services: Findings from the AESOP First Episode Psychosis Study’, Psychological Medicine $37,547-57$.

Derogatis, L.R. (1977) SCL-90-R: Administration, Scoring and Procedures Manual for the Revised Version (Baltimore, MD: John Hopkins University).

DUCKWORTH, J.C. \& W.P. ANDERSON (1995) MMPI and MMPI-2 Interpretation Manual for Counselors and Clinicians (4th ed.; Bristol, Pa: Accelerated Development).

EDDY, J.M. \& J.B. REID (2001) 'The Antisocial Behavior of the Adolescent Children of Incarcerated Parents: A Developmental Perspective' retrieved 30 May 2009 from http://aspe. hhs.gov/hsp/prison2home02/eddy.htm.

FARJAD, M.H. (1995) Social Psychology (Tehran: Asatir).

Feldman, R.A., T.E. CAPlinger, \& J.S. WodARski (1983) The St. Louis Conundrum: The Effective Treatment of Antisocial Youths (Englewood Cliffs: Prentice-Hall).

FORTH, A.E. \& H.C. BURKE (1998) 'Psychopathy in Adolescence: Assessment, Violence, and Developmental Precursors' in D.J. COOKE, A.E. ForTH \& R.D. HARE, eds. Psychopathy, Theory, Research and Implications for Society (Dordrecht: Kluwer) 205-29.

Frick, P.J., S.O. LiLienfeld, M.L. Ellis, B.R. LONEY \& P. SilverTHORN (1999) 'The Association between Anxiety and Psychopathy Dimensions in Children', Journal of Abnormal Child Psychology 27, 383-92.

Glenn, A.L., A. Raine, P.H. Venables \& S.A. Mednick (2007) 'Early Temperamental and Psychophysiological Precursors of Adult Psychopathic Personality', Journal of Abnormal Psychology 3, 508-18.

Gresham, F.M., K.L. LANE \& K.M. Lambros (2000) 'Comorbidity of Conduct Problems, ADHD: Identification of "Fledgling Psychopaths", Journal of Emotional and Behavioral Disorders 8, 15-33.

HALl, J.R., S.D. BenNING \& C.J. PATRICK (2004) 'Criterion-Related Validity of the Three-Factor Model of Psychopathy Personality, Behavior and Adaptive Functioning', Assessment 1, 4-16.

HARE, R.D. (1998) 'Psychopathy, Affect and Behavior' in D.J. CoOKE, A.E. ForTH \& R.D. HARE, eds. Psychopathy: Theory, Research and Implications for Society (Dordrecht: Kluwer) $105-37$.

Hare, R.D. (2003) Manual for the Hare Psychopathy Checklist - Revised (2nd ed.; Toronto: Multi-Health Systems).

HARRIS, G.T., M.E. RICE \& V.L. QUINSEY (1994) 'Psychopathy as a Taxon: Evidence that Psychopaths are a Discrete Class', Journal of Consulting and Clinical Psychology 62, 387-97.

Haskell, A. (1996) 'Mexican-American and Anglo-American Endorsement of Items on the MMPI-2 and Scale 2, the Center for Epidemiological Studies Depression Scale and the Cohen-Hoberman Inventory of Physical Symptoms', Dissertation at Texas Tech University, USA, retrieved 29 May 2009 from http://etd.lib.ttu.edu/theses/available/etd1125200831295011192019/unrestricted/31295011192019.pdf.

Hoagwood, K., P.S. Jensen, T. Petti \& B.J. Burns (1996) 'Outcomes of Mental Health Care for Children and Adolescents: A Comprehensive Conceptual Model', Journal of the American Academy of Child and Adolescent Psychiatry 35, 1055-63. 
KAZDIN, A.E. (1987) 'Treatment of Antisocial Behavior in Children: Current Status and Future Directions', Psychological Bulletin 102, 187-203.

KaZdin, A.E. (1993) 'Treatment of Conductive Disorder: Progress and Directions in Psychotherapy Research', Development and Psychopathology 5, 277-310.

KessleR, R.C. \& E.E. WALTERS (1998) 'Epidemiology of DSM-III-R Major Depression and Minor Depression among Adolescents and Young Adults in the National Comorbidity Survey', Depression and Anxiety 7, 3-14.

KHODARAHIMI, S. (2010) 'Snake Mother Imagery in Generalized Anxiety Disorder', International Forum of Psychoanalysis (in press).

Khodarahimi, S., A. Rasti, M. Khajehie \& R. Sattar (2009) 'Students' Mental Health: Personal and University Determinants', US-China Education Review 10, 31-38.

KUTASH, K. \& V.R. RIVERA (1996) What Works in Children's Mental Health Services: Uncovering Answers to Critical Questions (Baltimore: Brookes).

LIPSEY, M.W. \& J.H. DERZON (1998) 'Predictors of Violent or Serious Delinquency in Adolescence and Early Adulthood: A Synthesis of Longitudinal Research' in R. LOEBER \& D.P. FARRINGTON, eds. Serious \& Violent Juvenile Offenders: Risk Factors and Successful Interventions (Thousand Oaks, CA: Sage ) 86-105.

Logan, C. \& R. BlackBURN (2009) 'Mental Disorder in Violent Women in Secure Settings: Potential Relevance to Risk for Future Violence', International Journal of Law and Psychiatry 32, 31-38.

LORBER, M.F. (2004) 'Psychophysiology of Aggression, Psychopathy and Conduct Problems: A Meta-Analysis', Psychological Bulletin 130, 531-52.

Meloy, B.J.R. (1988) The Psychopathic Mind: Origins, Dynamics and Treatment (New Jersey: Aronson).

Mokhber, N., C. LANe, M.R. Azarpazhooh, E. SAlari, R. FAyazi, M.T. ShaKeri \& A.H. Young (2008) 'Anticonvulsant Treatments of Dysphoric Mania: A Trial of Gabapentin, Lamotrigine and Carbamazepine in Iran', Neuropsychiatric Disease and Treatment 1, 227-34.

Mousavinasab, S.M., M. Gorganinezhad-Moshiri, M. SAberifirouzi, G. Dehbozorgi \& D. MEHRABANI (2007) 'Personality Characteristics and Irritable Bowel Syndrome in Shiraz, Southern Iran', The Saudi Journal of Gastroenterology 13, 168-71.

NIMH (1999) 'Child and Adolescent Violence Research at the NIMH' retrieved 28 May 2009 from http://www.suite101.com/article.cfm/child_mental_illness/39412.

PARKER, K.C.H., R.K. HANSON \& J. HUNSLEY (1988) 'MMPI, Rorschach and WAIS: A MetaAnalytic Comparison of Reliability, Stability and Validity', Psychological Bulletin 103, 367-73.

Patterson, G.R., T.J. Dishion \& P. Chamberlain (1993) 'Outcomes and Methodological Issues Relating to Treatment of Antisocial Children' in T.R. GILES, ed. Handbook of Effective Psychotherapy (New York: Plenum) 43-88.

RutTER, M. (1979) 'Protective Factors in Childrens Responses to Stress and Disadvantage' in M.W. Kent \& J.E. Rolf, eds. Primary Prevention of Psychopathology: Social Competence in Children (Hanover, NH: UP of New England) 49-74.

SHAVER, P.R. \& C.L. CLARK (1994) 'The Psychodynamics of Adult Romantic Attachment', in J.M. MASLING \& R.F. BORNSTEIN, eds. Empirical Perspectives on Object Relations Theory (Washington, DC: APA) 105-56.

VAughan, S.C. \& J.M. OldHAM (1997) 'Behavioral and Adaptive Functioning' in A. TASMAN, J. KAY, \& J.A. LiEBERMAN, eds. Psychiatry (Philadelphia: Saunders) 549-62. 
PSYCHOPATHIC DEVIATE TENDENCY AND PSYCHOPATHOLOGY RELATIONSHIPS 111

Widiger, T.A. \& P.T. CostA (1994) 'Personality and Personality Disorders', Journal of Abnormal Psychology 103, 78-91.

WEIKART, D.P. (1998) 'Changing Early Childhood Development through Educational Intervention', Preventive Medicine 27, 233-37.

Williams, K.M. \& D.L. Paulhus (2004) 'Factor Structure of the Self-Report Psychopathy Scale (SRP-II) in Non-Forensic Samples', Personality \& Individual Differences 37, 76578.

ZAGON, I.K. \& H.J. JACKSON (1994) 'Construct Validity of a Psychopathy Measure', Personality \& Individual Differences 17, 125-35. 